\title{
The spatial characteristics and modernization embodiment of Convention and Exhibition Center--- Design of Bainiao River Convention and Exhibition Center
}

\author{
Yi Yang ${ }^{1, a}$, Siyu Ju ${ }^{2, b}$ and Muran Yang ${ }^{3, c}$ \\ ${ }^{1}$ Huazhong University of Science and Technology, Wuhan, Hubei, China \\ ${ }^{2}$ Huazhong University of Science and Technology, Wuhan, Hubei, China \\ ${ }^{3}$ Southeast University, Nanjing, Jiangsu, China \\ aemail:273842965@qq.com, bemail:656967024@qq.com,'email:mr9499@qq.com
}

Keywords: convention and exhibition center; regional feature; modernization; planning and design Abstract. With the example of The convention and exhibition center of Bainiao River, this paper discusses how the convention and exhibition center creates the space with regional characteristics and conforms to the development of the times by introducing the concept and design method of this project planning.

\section{Introduction}

The digital town of Baibiao River is the new type park that is planned and constructed by county Party committee of Huishui to accelerate the industrial transformation and upgrading and to explore newly path of industrialization. The park is located in the west of Huishui County with total planning area of 18 square kilometers and its starting location is 5 square kilometers in core area. The new industries in the park are mainly big date industry, education and culture industry, health and care industry, culture and tourism industry, and so on.

Location of the project:

Huishui County is located in the south of Guiyang City, and is situated in the south of Qianzhong Plateau. Its topography is that the north is higher than the south. The highest latitude is 1691 meters, the lowest latitude is 666 meters and the average latitude is 1100 meters. Huishui county is belonged to Qiannan Buyi and Miao antonymous region of Guizhou province, which straddles $106^{\circ} 22^{\prime} \mathrm{E}$ to $107^{\circ} 06^{\prime} \mathrm{E}$ and $25^{\circ} 41^{\prime} \mathrm{N}$ to $26^{\circ} 18^{\prime} \mathrm{N}$.Its total area is 2470 square kilometers .In the east, it borders Pingtang; in the west, it is bounded by Changshun; in the north, it adjoins Luodian in the south, it is neighboring to Guiyang and Longli.

The project is located in the east of Ximen Street of Bainiao River village, Haohuahong town, Huishui County with beautiful natural environment. The maximum length in north-south is about 189 meters, the narrowest distance in east-west is about 99 meters and the maximum width is about 135 meters. The total area of the project is 21,075 square kilometers and the overall construction area of the new comprehensive building is 32,000 square kilometers. The building is 5 floors with 4 floors in parts, and its height is 23.4 meters. The building's main functions are $\mathrm{R} \& \mathrm{D}$, work, education, training, conference, and space exhibition, which provides creative space for makers and creative park for youth.

\section{Conception}

In the process of project planning and design, combined with the regional characteristics of the project and the function of the exhibition center itself, the team carried out the following ideas.

\section{Cloud}

To help the implement of big data strategy and support the development of local economy, the government decide to use "Bainiao River digital town, Huishui, Guizhou province" as the base, adopt the operating model of "Beijing Front Shop, Guizhou Back Factory", and establish "HTC Internet Brand Precision Marketing Center" and "Jianan Wine Industry Online Marketing Center" in Bainiao 
River digital town. With the establishment of these companies, the Shenghua Team can help Guizhou build an influential big date Internet marketing base, which will make Huishui stand on the top of big date in southeast, and help Guizhou explore a new model of urbanization. According to the development and application program of big date industry in Guizhou province, Guizhou will center on the aspects of e-government, intelligent transportation, smart logistics, industry, e-commerce and food safety to create "QiDuoYun", it will make Guizhou people enjoy the "happiness index" from "big date".

Because the "cloud" is closely linked to big date, so it has been widely used as modeling elements of nonlinear architectural design. The free and smooth characteristic happens to coincide with the spirit of digital era. The project using "clouds" as one of the design concepts is a good echo of the big data strategy in Guizhou province.

\section{Memory of mountains}

In the world, there are many mountains in lots of countries and regions. Guizhou where is located in Yungui Plateau of China is a mountainous province. The geographical area of Guizhou province is 176,000 square kilometers, which accounts for $1.8 \%$ of Chinese national territorial area. Guizhou is the only province without plain, and $92.5 \%$ of area are mountains and hills. So, there is an old saying "eight mountains, one water and one field".

The hills are formed to special texture like paw prints, which belongs to the memory of people from mountains. The feature is grasped by the design and the texture transformed into architectural language is expressed by it, which is echoed to wonderful spirit of the place and strengthen the memory about the land where they grow up.

\section{Pear Flowers}

The song HaoHuaHong originated from Mao City, and the local Buyi people created this famous song. For hundreds of years, it was spread from generation to generation with long enduring singing. However, the new HaoHuaHong is sang by the group "Wonderful imprinting" who came from Guizhou province. The Musician Yuanze used the old song as introduction to create this new song. The pop music elements and the flowing melody bring the old song into people's life again. The wonderful performance from the group "Wonderful imprinting" let more people know the song.

The song echoes the local cultural context, and the element of flower is extracted as the language of architectural design. Meanwhile, it echoes very well the conception of "Cloud" and make the memory of cultural context integrate into new buildings preferably.

\section{Architecture Design}

\section{Plane layout design}

The main entrance of the building is located in the north side. Through the front square into the building, the sub-entrance the building is located in one floor of elevated landscape and parking garage. The whole building is divided into four floors of the North District and the five floors of the Southern District. The main functions of North part are R \& D, office, conference and exhibition. North part symmetrically sets up five traffic nuclear, seven walking ladder, four passenger ladder, a cargo elevator and four escalators.

There is a three-floors high atrium in the north side of the building. After entering the lobby, the crowd can go upstairs the second to fourth floor by the passenger ladder and the walking ladder on both sides of first floor. You can also walk through the ladder and escalator to every floor. The second floor of North District has two symmetrical sub-atriums which are two-floors high. This design is not only a good solution to the lighting problem of large space inside, but also enriched the building's interior space. From the plane modeling point of view, the North part consists of four elliptical space which are established contact each other through the traffic space. In the use of functions can not only be used alone, but take the form of large space. North part which mainly consists of large space, taking 
into account the flexibility of the function, tries to meet the different requirements of Creative space and Youth creative garden.

The southern part of the building is a five-storey interior corridor building, connected to the north through the inner gallery.There are separate entrances and exits in the south, and its main access is located at the ring road on the south side of the site. The main functions of southern district are education and training. There are three traffic nuclears, three walk ladders and three passenger ladders on this district.

\section{Facade Design}

The facade configuration of our design is inspired by the "mountain". Huishui County is surrounded by mountains and the Lianjiang river flows from north to South. Based on the land environment of the project, we put the building near the hill. Its appearance comes from the shape of four groups of oval hills and a mountain range. Meanwhile, white aluminum plates and grey glass curtain walls are used interchangeably as materials of building facade to copy the contour lines of mountains. Furthermore, the height of the building facades changes because the building is three floors, four floors and five floors partly to create a mood of undulating mountains. We are trying to make the facade of the building simple and brief, meanwhile the facade should steady and ordered which make it has rich levels on facade. The building considers the different space of modern office building requirements, building facades were carefully treated, the grey white aluminum and glass curtain wall, seemingly separate, but all blend into one harmonious whole. By means of using the ways of virtual-real comparison and block penetration, the building showing the sense of sculpture. With exquisite detail processing, the park enhance he value, cultural taste and city image.

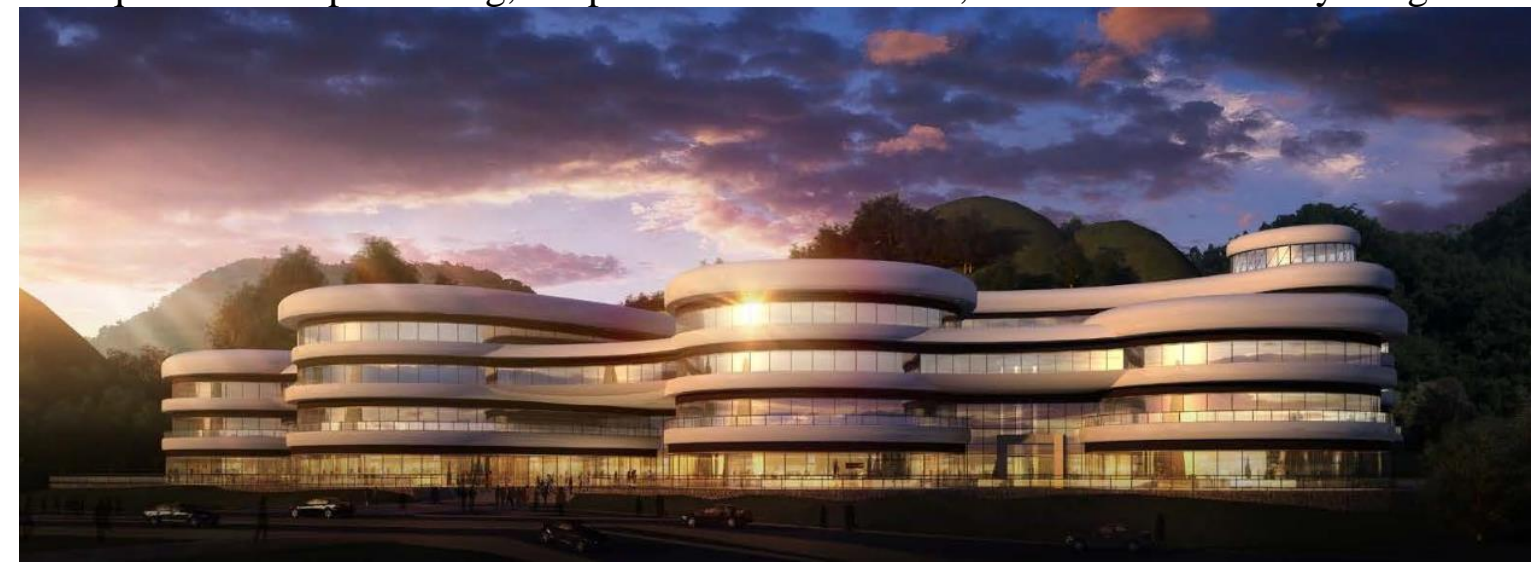

\section{Modern Development of Convention and Exhibition Center}

With the further development of city developing process, convention and exhibition center evoloved and improved. The innovation of convention and exhibition center in China started lately, however, it has highly improved due to decades of development. The architecture and management of convention and exhibition center will become more modernized.

\section{Construction}

The construction of convention and exhibition center not only refers to the construction of single building. According to foreign excellent experience of exhibition buildings, the current exhibition pavilions are not only the single supplier of the convention and exhibition centers, but more like a commercial complex. Like British Birmingham pavilion, it is built near Birmingham International Railway Station and Birmingham airport, and several highways approach the pavilion. Therefore spectators are easily accessible to pavilion, meanwhile, the pavilion is surrounded by several hotels. Restaurants and cafes are distributed in the pavilion and the login hall both.

\section{Smart Exhibition}

With the development of science and technology, the exihibition model will have a great innovation. The smart exihibition which relies on the internet will be the new exihibition model. 
"Smart-exihibition" refers to a new exhibition platform, which relies on the internet, big data, cloud computing, artificial intelligence and other new generation of information technology. In the way of the integration of online and offline, integrates all kinds of Business flow, logistics and logistics integration, thus achieving a high degree of integration of intelligent technology, intelligent exhibition of high-end development, making the exhibition integration service system which joining marketing, operations, products and services together.

\section{Integration of resources}

Throughout the history of foreign exhibition, we can find that most of the city's exhibition development has gone through a process from divergence to concentration.

The first stage: decentralized management, the no correlation private companies and state-owned exhibition companies develop themselves without competition.

The second stage: after the elimination of the market and the integration of the industry, many of the exhibition companies have withdrawn from the market, leaving only a small proportion of the larger exhibition groups or companies.

The third stage: the exhibition market will be further integrated, the exhibition organizations which represent city brand will appear and then participate in the competition with foreign brands.

For example, the exhibition industry is developing very well in Germany , and there form some large exhibition institutions which represent City brand. They integrate many of the city's resources, thus, they build a new exhibition model that every pavilion can not only exhibition alone but also mutual cooperation in international exhibition.

\section{Conclusions}

The concept and function of Exhibition center will develop with the further development of the human society. In the future, the conference and exhibition center will be a green building which provide the participants with a multi-functional building based on the Internet for large-scale exhibitions of different urban resources.

I believe that with the development of the country, China's exhibition industry will become more and more prosperous and modernized.

\section{References}

[1] Weiwen Gao: Innovation and Application of Green Building Technologies in National Exhibition and Convention Center (ShangHai). Green Building 2006-03-20, In Chinese

[2] ChunCai Wang: Research on the development path and strategy of the Convention and Exhibition Center in Germany. Beijing: Beijing Union University, 2010-01-20, In Chinese

[3] Chao Jiang, The Research for Commercial Exhibition Design Under the Tendency of the Smart Exhibition. Nanjing Forestry University, 2016-06-01, In Chinese

[4] Peng Yu: A Study on Qingdao International Convention Center's Development Model. Tianjin Universty, 2007-12-01, In Chinese 